\title{
Identidades em devir: um processo dinâmico, contínuo e inacabado
}

\author{
Reinventing Identities: The \\ Gendered Self in Disc ourse.
}

BUC HO LTZ, Mary, LIANG, A. C., and SUTTON, Laurel, A.

New York: Oxford University Press, 1999. $431 \mathrm{p}$.

O livro Reinventing Identities: The Gendered Self in Disc ourse, orga niza do pelas a utoras Mary Bucholtz, A. C. Liang e Laurel A. Sutton, é uma compilação de artigos sobre como identidades escolhidase impostas são criadas, formatadase alteradas a tra vés do tempo, lugares, falantes e contextos. Os 20 artigos, distribuídos em qua tro partes, abordam identida de como um repertório de possibilidades, do qual os/as a tores/as soc ia is lançam mão, dependendo da situação. "Id entida de como invenção", "Identida de como ideologia", "Identidade como ingenuidade" e "Identidade como improvisação" abordam a temática de forma intere transdisciplinara o longo de 431 páginas. Os textos representam uma expansão da teoria feminista dos anos 70 e 80 , pois já não tratam identidade de forma essencialista, desligada de a travessamentos constitutivos como raça, etnia, sexualidade, classe social, naciona lida de e outras dimensões sociais. A obra também desmistifica o uso de expressões genera lizantese unific a das como "uso da linguagem pormulheres", "cultura dominante", pois sustenta que as id entida des são negociadas a tiva mente e não existentes a priori.

Bucholt fala da relação difícil da teoria feminista com a linguagem e pesquisa de gênero. Isso se dá, em parte, pela nova visão de identidade que as pesquisas têm trazido. Não assumindo mais a identidade como uma categoria estática, mas como atividade semiótica, já não se pode falar em "grandes patriarcados opressores", por exemplo. O determinismo histórico das superestruturas (maquinarias sociais), que reivindica a idéia de sujeito tomado, fica, portanto, relativizado. A negociação de identidades múltiplas oferece, nessa nova ótica, uma ruptura com a visão de categorias e poder hegemônicos. Butler, citada por Bucholtz, Liang e Sutton, loca liza no corpo o estágio sobre o qual o gênero é representado, onde elementos do self são projetados e naturalizados ou não. O que passa a ser considerado é um balanço entre agência individual e desigualdades estrutura is, fazendo com que vozes múltiplase subversivas substituam passividade, opressão e silêncio por ação.

A idéia de "comunidades de prática" 1 revolucionou a pesquisa sobre linguagem e gênero. Essa nova perspectiva teóricometodológica propiciou um olhar para as experiências localmente situadas. Nas comunida des, os/as partic ipantes a ssumem uma variedade de identidades, cuja relevância varia de momento para momento. Um dos desafios para o/a pesquisador/a em comunidades de prática é observarcomo as pessoas se movem e a gem, sem a va liações sobre o que é a dequado ou não.

A primeira parte do livro, "Identity as Invention", das autoras Marcyliena Morgan, Kathleen Wood, Marjorie Faulstich Orellana, Lisa Capps e Sara Trechter, localiza os processos invisíveis de construção de identidades a través do uso da linguagem, questionando a idéia de que identidades de gênero são inevitáveis, natura is e fixas. Seres soc ia is sã o, para as a utoras, produzidos na interação, através de processos de resistência ou alinhamento. Esse processo é sempre dialógico, no sentid o bakhtinia no, pois o "eu" é negoc ia do a tra vés do "tu". Osartigos dessa parte do livro lançam um olhar suspeito pa ra tudo aquilo que é inocentemente tomado como natural. A lista do que é considerado natural é quase infinita, abarcando fenômenos cognitivos, biológicos, psicológicos e ideológicos, que 'explicam' a 'natureza' do sujeito. A neurose, tão associada ao 'comportamento feminino' pode, porexemplo, ser reforçada lingüistic a mente pelas práticas circulares das famílias, uma vez que a palavra é tomada como ação. Da mesma forma, inúmerascarac terístic as to ma das como 'na tura is' em homens e mulheres são, na verdade, produzidas socialmente e reforçadas sistematic a mente pela linguagem. 
A segunda parte do livro "Identity as Id eology", de J enniferCoates, Ca itlin Hines, Laurel Sutton, Rebecca Dobkins e Keith Walters, explora a multiplicidade de meios utilizados para perpetuar e impor identidades a través da linguagem. A ideologia é construtora de identidades, não se questiona, mas ela está em permanentes processos de mudança e revisão por ind ivíduos e grupos. As metá foras constituem um meio efic az de natura lização de concepções a través da língua. Dentre muitas, estão as que associam a mulher à comida, sempre cortada em pedaços ou fatias, que acabam pordiminuir a mulher, negando-lhe a unidade e relegando-a a um objeto de satisfação do desejo do outro.

Apesar de se refutar essencialismos biológicos, é importante, porém, não esquecer que os indivíduos têm corpos. 0 corpo toma-se um espaço de inscrição da história, o que traza perspectiva da linguagem como prática corporeificada. Segundo Bourdieu, o habitus é uma série de disposições que inclinam agentes a agir e reagir de determinadas formas. Essas disposições são a dquiridas a tra vés do processo de socialização e representam os meios pelos quais o corpo atualiza a estrutura social internalizada e se orienta física e psicologicamente para o mundo. ${ }^{2}$ É a natureza corporeific a da de atitudes lingüístic as que explic a variantes fonéticas e uso de expressões tidas como masculinas ou femininas, por exemplo. Como se vê, é o aspecto social incidindo sobre o biológico, o que toma problemática qualquer c lassific ação identitária como natural.

O terceiro bloco da obra, "Identity as Ingenuity", das/os autoras/es Deborah Tannen, Patrícia Sawin, William Leap, Norma Mendoza Denton e A. C. Liang, trata da linguagem no seu aspecto criativo e ambíguo, utilizada por categorias 'desviantes' dos padrões para evitar o confronto com categorias socia is está veis. Isso inc lui a escolha lexical em interações específic as entre gays e lésbicas, por exemplo, que querem ocultar sua identidade para se proteger da homofo bia. Os a gentes homossexua is tra ba lha $\mathrm{m}$ dentro e contra ideologias cultura is de id entidade para construir uma identidade consc ientemente escolhida. A ênfase aqui é, novamente, na identidade gay como processo de construção social, a o invés da exaltação a o essencialismo estátic o da homossexua lida de.

É importante destacar que muitas pessoas incorrem na ingenuidade de loca lizardiferenças de gênero no indivíduo, ao invés de na relação entre indivíduos. É preciso a tentar para o tipo de alinhamento que os/as falantes estão tendo; como se posicionam em relação à situação e onde mulhere homem tendem a cairem padrões de comporta mento. Dessa forma, a relação entre linguagem e gênero é mais bem entendida quando o foco de atenção é a situação, o evento. A interação é sempre atravessada por diversos fatores que se alteram, perturbam e interferem mutuamente, tais como classe social, escolaridade, a utoridade, poder.

A quarta e última parte do livro, "Identity as Improvisation", de Rusty Barrett, Anna Lívia, Mary Bucholtz, Colleen Cottere Marjorie Goodwin, traz à tona osnovosarranjos socia is que providenciam os signific a dos para construir novas id entida des. Identidade, ao invés de uma instância determinada, é algo construído e reificado continuamente. É importante ter em mente que a linguagem não é a única formadora de id entida des, mas sistemas inteiros de a tividades. As drag queens, por exemplo, ao se manifestarem, podem estar celebrando a dissolução das categorias de gênero. Sua linguagem é a mbivalente, crítica e, às vezes, raivosa. Vários estilos indexic a lizam uma identidade múltipla e política, que protesta contra a homofobia, racismo e todos os preconceitos contra os/as que não se enquadram na 'nomalidade'.

Ao passo que algumasfeministas condenam a performance das drag queens como misógena, teóric as defendem que elas tratam da subversão ou inversão de questões de gênero tra diciona is. Teorias queer, também chamadas de teorias feministas pós-estruturalistas, glorificam a drag como uma força desconstrutiva altamente política, trabalhando para minar questões de gênero. Segundo essa teoria, as drags não debocham das mulheres, mas se vêem também lutando contra opressões de gênero, o que, por si, merec eria a poio das feministase não desdém. Cla ro que não esta mos, como em nenhuma outra parte, falando de identidades monolíticas, e por isso não podemos a tribuir característic as unidimensionais às drags. Elas não são inerentemente subversivas ou misógenas. Há que se lembrarque as pessoas têm um "repertório de identidades" e que, em dado momento, é pinçada uma entre várias outras.

Refazendo o caminho da pesquisa em Linguagem e Gênero, podemos definir três estágios. Os anos 70 representaram a década da descoberta. Os anos 80, um período de crítica e correção do trabalho anterior. A década de 90 , período conhecido como a "terceira onda", foi o período transformador, trazendo novas questõese áreas inexploradas. A partirda terceira 
onda os sig nific a dos sã o c onstruíd os loc a lmente, ao invés de se acreditar em divisões globa is de gênero. Olhar para as variações individua is e para a lém das categorias de gênero significa libertar as identidades do seu engessamento tradicional. Admitir identidades cheias de possibilidades pode ta mbém contribuir para que as pessoas comecem a explorarnovas maneiras de se expressar no mundo. Isso, sem dúvida, é ousa do, principalmente quando se a prendeu que as coisas são assim porque "Deus" ou a na tureza quis e já vêm de tão longe que nem sequer se pensa na possibilidade de serem diferentes. Esse é o grande aspecto transg ressore liberta dordesse tipo de pesquisa. As verdades e as obviedades são 'c onvocadasa se justific ar'; já não sustentam ma is seu sta tus de legitimida de.

Esse livro, por todos os aspectos citados, é altamente recomendado a todos que ousam refletir sobre a complexa questão da lingua gem e forma ção das identida des. É, sem dúvida, uma senda que pode trazer conflitos, revelações, grandes insights. Pode, sobretudo, proporcionar momentos ricos de pensar na identidade como uma possibilidade multifacetada. Binarismos simplistas, maniqueísmos ingênuos e expressões genera lizantes não sa tisfa rão ma is, por certo, o/ a leitor/a, depois dessa experiência de leitura.

\section{Notas}

${ }^{1}$ Etienne WENGER, 2004.

2 Pierre BOURDIEU, 1977.

\section{Referências bibliográficas}

BOURDIEU, Pierre. "The Economics of Linguistic Exchanges." Social Science Information, v. 16, n. 6, 1977. p. 645-668.

WENGER, Etienne. Communities of Practice: Learning, Meaning and Identity. New York: Cambridge University Press, 2004.

Mariléia Sell Universidade do Vale do Rio dos Sinos 